\title{
ARTICLE
}

Body composition, energy expenditure and physical activity

\section{Reference values for body composition and associations with blood pressure in Kenyan adults aged $\geq 50$ years old}

\author{
Madeleine C. Bastawrous $\mathbb{1}^{1} \cdot$ Carmen Piernas $\mathbb{1}^{1} \cdot$ Andrew Bastawrous $^{2} \cdot$ Jason Oke $^{1} \cdot$ Daniel Lasserson $^{3} \cdot$ \\ Wanjiku Mathenge ${ }^{4,5} \cdot$ Matthew J. Burton ${ }^{3,6} \cdot$ Susan A. Jebb ${ }^{1} \cdot$ Hannah Kuper ${ }^{2}$
}

Received: 10 September 2017 / Revised: 26 March 2018 / Accepted: 28 March 2018 / Published online: 15 May 2018

(c) The Author(s) 2018. This article is published with open access

\begin{abstract}
Background/objectives To develop age- and sex-specific centile reference curves for fat-free mass (FFM) and fat mass (FM) adjusted for height in an adult Kenyan population and to investigate the association between FM, FFM and blood pressure (BP). Subjects/methods Measures of body composition from bioimpedance analyses and BP were collected in 1995 participants aged $\geq 50$ years in Nakuru County, Kenya. Reference curves were produced using the LMS method. Multivariable linear regression models were used to test the cross-sectional association between body composition indexes and BP.

Results The age- and sex-specific reference curves for body composition (FMI and FFMI) confirmed that FFMI is lower in both men and women with increasing age. FMI declines with age in women while among men the decline starts after 70 years. FFM was higher in men $(47.4 \pm 7.2 \mathrm{~kg})$ than in women $(38.8 \pm 5.5 \mathrm{~kg})$, while FM was lower in men $(17.3 \pm 8.1 \mathrm{~kg})$ than in women $(24.4 \pm 10.2 \mathrm{~kg})$. FMI, FFMI and BMI were all positively associated with systolic and diastolic BP, and after adjusting for body weight, FFMI remained positively associated with systolic BP and the FMI remained positively associated with diastolic BP. There was no evidence to suggest that FMI and FFMI were superior to measurement of BMI alone. Conclusions These body composition reference curves provide normative data on body composition for older adults in Kenya. Further research should consider the prospective associations with health, including frailty-related outcomes.
\end{abstract}

\section{Introduction}

There is growing interest in the effect of body composition, beyond body weight, on health outcomes linked to aging

Electronic supplementary material The online version of this article (https://doi.org/10.1038/s41430-018-0177-z) contains supplementary material, which is available to authorized users.

Madeleine C. Bastawrous

madeleine.bastawrous@phc.ox.ac.uk

1 Nuffield Department of Primary Care Health Sciences, University of Oxford, Oxford, UK

2 International Centre foer Eye Health, Clinical Research Department, London School of Hygiene \& Tropical Medicine, London, UK

3 Department of Geratology, Oxford University Hospitals NHS Foundation Trust, Oxford, UK

4 Rwanda International Institute of Ophthalmology, Kigali, Rwanda

5 The Fred Hollows Foundation, Nairobi, Kenya

6 Moorfields Eye Hospital, London, UK
$[1,2]$. Traditionally, nutritional assessment has relied upon the body mass index (BMI) (weight/height ${ }^{2}$ ), which is easy, cheap and convenient to measure, but it is limited because the relative proportion of fat mass (FM) and fat free-mass (FFM) is unknown. Changes in body weight may be due to changes in FM, FFM or both. Although there is a positive correlation between FFM and body weight within populations, FFM cannot always be accurately predicted from weight or BMI at an individual-level [2], and changes in BMI may obscure underlying shifts in the proportion of FM and FFM.

Bioelectrical impedance analysis (BIA) is a simple, portable, inexpensive and non-invasive technique to assess FFM and FM [3]; however, the use of body composition measurements in routine health surveillance and in clinical practice is limited by the lack of reference data to allow the classification of individuals at risk across the age spectrum. Centile charts have been developed to describe changes in FM and FFM throughout childhood [4, 5] and for adults in high- and middle-income countries [6-9]. However, body composition varies by population [10, 11], and loss of FFM may be related to ethnicity, diet, physical inactivity or 
disease in older adults $[12,13]$. Reference data are especially limited in African populations [12] and resource-poor settings [14]. Population-specific body composition reference data will help to elucidate age-related changes associated with ill-health, and will allow more accurate characterization of individuals at greatest risk of disability and morbidity so they can receive targeted support. This is especially important in low- and middle-income countries where the double burden of non-communicable diseases (NCDs) and infectious disease coupled with limited health systems means that healthcare resources need to be carefully prioritized [15-18].

There is growing evidence that FM and FFM are independent risk factors for NCDs. FM has been shown to be strongly associated with increased risk of chronic diseases such as hypertension, hyperlipidemia and insulin resistance [19]. Conversely, reductions in FFM are characteristic of aging and independently associated with worse health outcomes and disabilities [20, 21], leading to frailty, reduced life expectancy in healthy subjects and impaired quality of life associated with weakness, alongside increased personal and healthcare costs [22-24]. In addition, loss of FFM, or more specifically skeletal muscle mass (SMM) in combination with increased adiposity, known as sarcopenic obesity, is increasingly recognized as a major health concern in the aging population because of its association with a higher risk of cardiometabolic and functional abnormalities [25]. A previous study found an increased risk of hypertension among those with sarcopenic obesity [26].

This study aimed firstly to develop age- and sex-specific centile reference curves for FFM and FM derived from BIA in an adult Kenyan population. Secondly, we aimed to investigate the association between demographic characteristics and body composition measures; and to compare the predictive value of FFM and FM relative to BMI for the association with systolic and diastolic blood pressure (BP).

\section{Methods}

\section{Study population}

This study used data from a subsample of participants ( $n=$ 1995) from the longitudinal Nakuru Eye Disease Cohort Study [27]. The primary aim of the study was to establish a survey which formed the baseline to a 6-year prospective cohort study to estimate the incidence and progression of eye disease in this population and the data collection reflected these goals. The initial study population was determined following a baseline population-based survey conducted in 2007-2008 with the aim of recruiting a sample of $\sim 5000$ participants aged $\geq 50$ years, based on an expected prevalence of a visual acuity of $<6 / 12$ in the better eye caused by posterior segment disease of $3.0 \%$. A total of 100 clusters each of 50 participants were selected with a probability proportional to the size of the population across Nakuru district. Households were selected within clusters using a modified compact segment sampling method. In total, 4381 participants at baseline (87.4\% response rate) underwent complete examination across 100 clusters. A follow-up examination was conducted 5.6 years later (January 2013 to March 2014), in which 2170 (50\%) participants were followed up. Among these, 1995 participants $(n$ $=950$ men and $n=1045$ women, $92 \%$ of the follow-up sample) had complete data on body composition and BP, which was used for the present analysis.

Further details of all the procedures undertaken for all participants who attended an examination clinic at baseline and follow-up are available elsewhere [27]. Structured interviews were performed in the participant's preferred language covering (i) demographic; (ii) past medical and ocular history including medication and relevant family history; (iii) known NCD risk factors; and (iv) socioeconomic status based on job, housing conditions, ownership of material goods and livestock which is translated in to a score based on previous work in the same population [28].

The study adhered to the tenets of the Declaration of Helsinki and was approved by the Ethics Committee of London School of Hygiene \& Tropical Medicine (LSHTM Ref 6192) and by the African Medical and Research Foundation (AMREF) Ethics Committee (AMREF-ESRC $\mathrm{P} 44 / 12)$.

\section{Anthropometry and BIA}

As per protocol, a nurse recorded measures for height (m) (Leicester Height Measure, Chasmors Ltd, London) and weight (kg) (Seca 761, Williams Medical Supplies, London). BMI was calculated as the weight $(\mathrm{kg})$ divided by the squared height $(\mathrm{m})$. BIA was performed in non-fasting and resting conditions, using a Tanita Segmental Body Composition Monitor (BC-601, Tanita Corp). This study used data on FM and FFM, calculated as the sum of the predicted total muscle mass (which includes skeletal and smooth muscle and the water contained in those) and bone mineral mass.

Consistent with previous studies $[9,29,30]$ and in order to account for the fact that people with the same body weight and FM percentage who differ in height will have different body composition status, height-adjusted indexes for body composition were calculated: FMI (fat mass/ height $^{2}$ ) and FFMI (fat-free mass/height ${ }^{2}$ ).

\section{Blood pressure}

Three measurements of systolic and diastolic BP were taken using an Omron Digital Automatic Blood Pressure 
Monitor (HEM907, Omron) after the study participant had been seated for at least $10 \mathrm{~min}$ and each reading was taken 10 min apart. The mean of the three measurements was used.

\section{Development of centile curves}

Centile curves were constructed for men and women separately using the LMS method, which summarizes the data in terms of three smooth age-specific curves, namely L (lambda), $\mathrm{M}$ (mu) and S (sigma) [31]. The $\mathrm{M}$ and $\mathrm{S}$ curves correspond to the median and coefficient of variation of each body composition measure at each age, whereas the $\mathrm{L}$ curve allows for the age-dependent skewness in the distribution of each body composition measure. The LMS function from the R package GAMLSS was used to estimate age-specific centile curves [32, 33]. Following the same format of other growth reference curves [4, 5], centile curves for FFMI and FMI were calculated, from the 2nd to the 98th percentiles, spaced two-thirds of an SD score apart.

\section{Statistical analyses}

Stata version 14 was used for the statistical analyses. For descriptive analyses, means (SD) or samples (\%) were used to describe demographic characteristics, anthropometric and health characteristics among men and women separately. Mean FMI and FFMI in each percentile were summarized for different age groups: $50-59,60-69 ; 70-79 ; 80+$. Four multivariable linear regression models were used to describe the population characteristics associated with each body composition index (i.e., FFMI and FMI) as well as for the BMI. Mean values were predicted for each demographic characteristic. The means presented are unconditional means calculated by averaging over the other variables in the model rather than estimating the means at fixed levels of the other covariates (reference levels). Four independent multivariable linear regression models were run to obtain beta coefficients $(95 \%$ confidence interval (CI)) for the association between each measure (FFMI, FMI and BMI) and systolic and diastolic BP with adjustment for confounding variables such as age, gender, tribe, urban/rural, education, smoking and alcohol intake. In order to compare the predictive value between each body composition index (FFMI and FMI) and BMI, partial Pearson's correlation coefficients were obtained from the above multivariable models. Values of each body composition index and BMI were standardized into $z$-scores before running the models to allow comparison of their partial Pearson's correlation coefficients.
Table 1 Demographic characteristics of the study population

\begin{tabular}{llllll}
\hline & \multicolumn{2}{l}{ Men $(n=950)$} & & $\begin{array}{l}\text { Women } \\
(n=1045)\end{array}$ \\
\cline { 2 - 3 } \cline { 5 - 6 } Demographic characteristics & Mean/n & SD/\% & & Mean/n & SD/\% \\
\hline Age (years) & 67.8 & 8.7 & 66.6 & 8.9 \\
Maximum education level & & & & \\
None & 162 & 17.1 & 482 & 46.1 \\
Primary & 525 & 55.3 & 409 & 39.1 \\
Secondary/college/university & 252 & 26.5 & 130 & 12.4 \\
Missing & 11 & 1.2 & 24 & 2.3 \\
Socioeconomic status & & & & \\
1 quartile (poorest) & 244 & 25.7 & 220 & 21.1 \\
2 quartile & 194 & 20.4 & 228 & 21.8 \\
3 quartile & 186 & 19.6 & 241 & 23.1 \\
4 quartile (richest) & 187 & 19.7 & 183 & 17.5 \\
Missing & 139 & 14.6 & 173 & 16.6 \\
Tribe & & & & \\
Mixed & 132 & 13.9 & 115 & 11.0 \\
Kikuyu & 559 & 58.8 & 702 & 67.2 \\
Kalenjin & 259 & 27.3 & 228 & 21.8 \\
\hline
\end{tabular}

\section{Results}

\section{Participant characteristics}

From a total of 2170 Kenyan adults, a high proportion of participants had no education $(17.1 \%$ men and $46.1 \%$ women) or only primary education $(55.7 \%$ men and $31.8 \%$ women). The predominant tribal group was Kikuyu (Table $1)$.

Mean BMI was within the healthy range for men: $23.1 \pm$ 4.4 and in the overweight range for women: $26.1 \pm 5.6 \mathrm{~g} / \mathrm{m}^{2}$ (Table 2). The prevalence of obesity was lower in men (7.2\%) compared to women (25.5\%). FFM was higher in men $(47.4 \pm 7.2 \mathrm{~kg})$ than in women $(38.8 \pm 5.5 \mathrm{~kg})$, while FM was lower in men $(17.3 \pm 8.1 \mathrm{~kg})$ than in women $(24.4$ $\pm 10.2 \mathrm{~kg}$ ). Mean systolic BP for men was $134.0 \pm 23.1 \mathrm{~mm}$ $\mathrm{Hg}$ and $130.8 \pm 24.2 \mathrm{~mm} \mathrm{Hg}$ for women. Mean diastolic BP was $82.7 \pm 13.1 \mathrm{~mm} \mathrm{Hg}$ for men and $82.6 \pm 12.9 \mathrm{~mm} \mathrm{Hg}$ for women. The majority of men and women never smoked (73.7\% and $98.4 \%$, respectively). A higher proportion of men consumed alcohol in the past or currently $(55.7 \%$ and $25.3 \%$, respectively) compared to a higher proportion of women who never consumed alcohol (60.1\%).

\section{Body composition reference values}

Figure 1a-d shows age- and gender-specific centiles curves for FFMI and FMI. FFMI demonstrated a relatively consistent and significant rate of decline with age for both men and women (Fig. 1a, b). At the median, FFMI for men is 
Table 2 Health-related participant characteristics

\begin{tabular}{|c|c|c|c|c|}
\hline & \multicolumn{2}{|c|}{$\operatorname{Men}(n=950)$} & \multicolumn{2}{|c|}{$\begin{array}{l}\text { Women } \\
(n=1045)\end{array}$} \\
\hline & Mean $/ n$ & $\mathrm{SD} / \%$ & Mean $/ n$ & $\mathrm{SD} / \%$ \\
\hline Weight (kg) & 64.7 & 13.5 & 63.2 & 14.8 \\
\hline Height $(\mathrm{cm})$ & 167.2 & 7.0 & 155.4 & 6.6 \\
\hline BMI $\left(\mathrm{kg} / \mathrm{m}^{2}\right)$ & 23.1 & 4.4 & 26.1 & 5.6 \\
\hline \multicolumn{5}{|l|}{ BMI category } \\
\hline Underweight $\left(<20 \mathrm{~kg} / \mathrm{m}^{2}\right)$ & 126 & 13.3 & 76 & 7.3 \\
\hline Normal weight $\left(20-25 \mathrm{~kg} / \mathrm{m}^{2}\right)$ & 530 & 55.8 & 400 & 38.3 \\
\hline Overweight $\left(25-30 \mathrm{~kg} / \mathrm{m}^{2}\right)$ & 226 & 23.8 & 303 & 29.0 \\
\hline Obese $\left(>30 \mathrm{~kg} / \mathrm{m}^{2}\right)$ & 68 & 7.2 & 266 & 25.5 \\
\hline FFM (kg) & 47.4 & 7.2 & 38.8 & 5.5 \\
\hline FFMI $\left(\mathrm{kg} / \mathrm{m}^{2}\right)$ & 16.9 & 2.1 & 16.1 & 1.9 \\
\hline FM $(\%)$ & 25.6 & 7.7 & 37.1 & 8.2 \\
\hline FM (kg) & 17.3 & 8.1 & 24.4 & 10.2 \\
\hline FMI $\left(\mathrm{kg} / \mathrm{m}^{2}\right)$ & 6.2 & 2.9 & 10.1 & 4.1 \\
\hline FFM to FM index & 3.4 & 1.8 & 1.9 & 1.0 \\
\hline \multicolumn{5}{|l|}{ Blood pressure } \\
\hline Systolic (mm Hg) & 134.0 & 23.1 & 130.8 & 24.2 \\
\hline Diastolic (mm Hg) & 82.7 & 13.1 & 82.6 & 12.9 \\
\hline \multicolumn{5}{|l|}{ Smoking status } \\
\hline Never & 700 & 73.7 & 1,028 & 98.4 \\
\hline Former & 125 & 13.2 & 3 & 0.3 \\
\hline Current & 97 & 10.2 & 5 & 0.5 \\
\hline \multicolumn{5}{|l|}{ Alcohol consumption } \\
\hline Never & 167 & 17.6 & 628 & 60.1 \\
\hline Former & 529 & 55.7 & 332 & 31.8 \\
\hline Current & 240 & 25.3 & 65 & 6.2 \\
\hline
\end{tabular}

$17.3 \mathrm{~kg} / \mathrm{m}^{2}$ at 60 years and declines to $15.3 \mathrm{~kg} / \mathrm{m}^{2}$ at 90 years (Supplemental Table 1). The younger women began with a lower FFMI than for men but followed a similar pattern with a median FFMI at 60 years of $16.4 \mathrm{~kg} / \mathrm{m}^{2}$ declining to $14.5 \mathrm{~kg} / \mathrm{m}^{2}$ at 90 years.

FMI for men peaked between 60 and 70 years, followed by a gentle decline before stabilizing between 80 and 90 years (Fig. 1c). In women, FM shows an on-going decline as age increases (Fig. 1d). The decline in men began at 60 years with a lower FMI of $5.7 \mathrm{~kg} / \mathrm{m}^{2}$, decreasing to $5.3 \mathrm{~kg} /$ $\mathrm{m}^{2}$ at 90 years. Women however started at 60 years with a median FMI of $10.7 \mathrm{~kg} / \mathrm{m}^{2}$ and reduced to $7.9 \mathrm{kgm}^{2}$ at 90 years.

\section{Sociodemographic correlates of body composition}

Multivariable linear regression models were used to investigate associations between each body composition measure and demographic and lifestyle characteristics (Table 3). Consistent with the results shown in the centile curves, mean FFMI was significantly lower in older age groups in both men and women, while FMI was significantly lower in older ages only among women. BMI was significantly lower in older age groups among men and women.

Men and women from urban areas had a significantly higher FFMI, FMI and BMI than those from rural areas. Among participants with secondary education and above compared to those with no education, men had significantly higher FFMI and BMI, whereas women had significantly higher FFMI, FMI and BMI. Compared to never smokers, men who currently smoked had significantly lower FFMI, FMI and BMI. Among women, those currently consuming alcohol had a significantly lower FFMI, FMI and BMI compared to those who never consumed alcohol.

\section{Associations of body composition measures and BMI with BP}

Table 4 shows standardized beta estimates and partial correlation coefficients for the association between each body composition measure and BP after adjustment for age, gender, tribe, urban/rural, education, smoking and alcohol intake. BMI, FFMI and FMI are all positively associated with both systolic and diastolic BP with correlation coefficients ranging from 0.13 to 0.22 . After adjusting for body weight the associations were weakened. However, FFMI remained significantly positively associated with higher systolic BP and FMI with higher diastolic BP.

\section{Discussion}

This analysis presents novel age- and sex-specific reference curves for body composition (FMI and FFMI) in an older Kenyan population. This study confirms that FFM is lower in both men and women at older ages. FM also declines with age in women while among men the decline starts after 70 years. FMI, FFMI and BMI were all positively associated with systolic and diastolic BP, and after adjusting for body weight, the FFMI remained positively associated with systolic BP whereas the FMI remained positively associated with diastolic BP.

Most reference values for body composition are focused on predominately white populations from Sweden, Switzerland, the United Kingdom and the United States, with only a limited number of other non-white populations, including Japanese, African Americans and Mexican Americans [9, 11, 12, 14, 34, 35]. To our knowledge, there are no reference values for body composition specifically derived for Black African populations. The Japanese women have the lowest overall FFMI followed by similar FFMI for each age category from the Kenyan and Swedish populations; both the White and African American 
Females

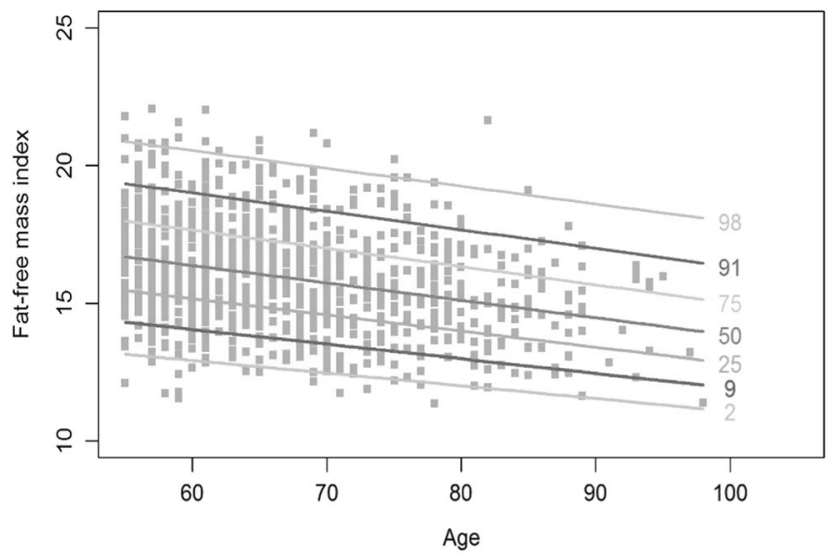

Females

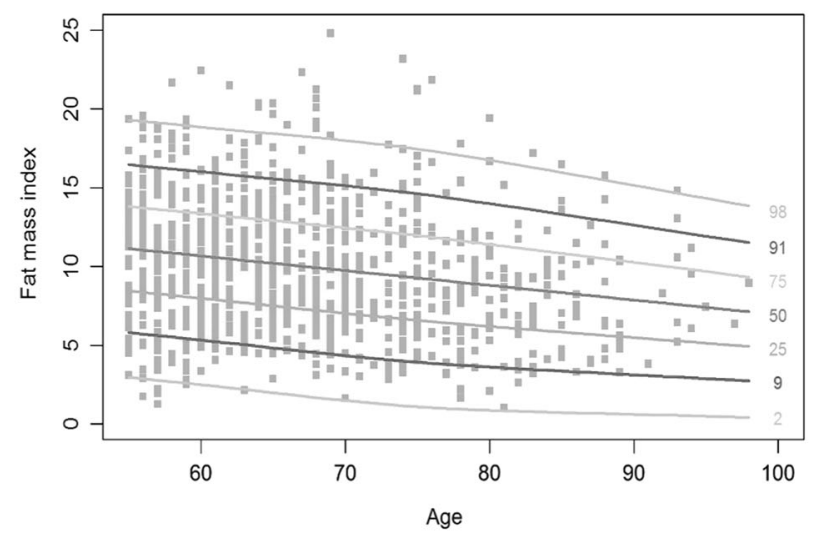

Males

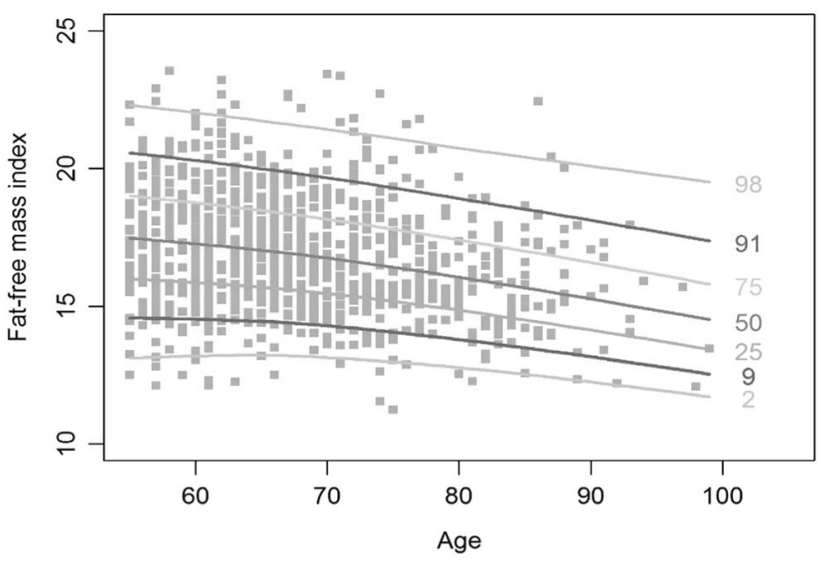

Males

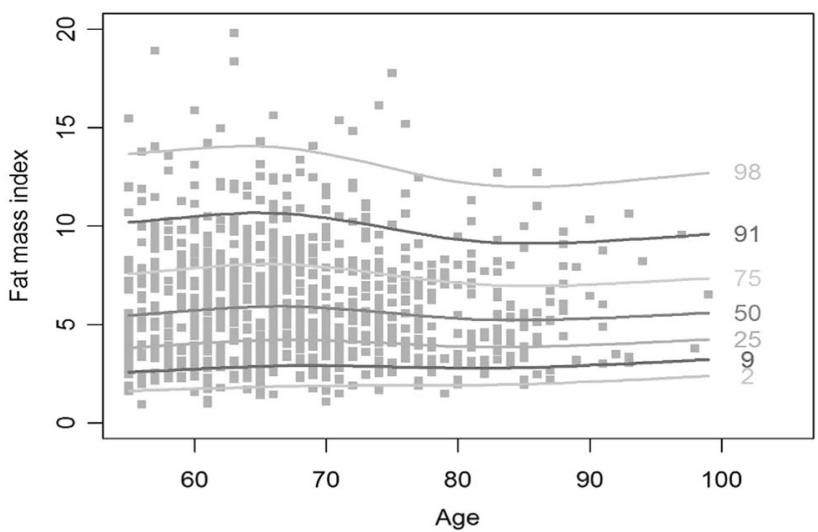

Fig. 1 Age- and sex-specific centile reference curves for fat-free mass (FFM) and fat mass (FM) adjusted for height

populations have the overall highest FFMI across the age categories. For men, the Kenyan population has lowest mean FFMI for each age category followed closely by the Japanese population. The male Swedish and both American populations have significantly higher FFMI for each age category. All ethnicities show a trend towards gradual decreasing FFMI for men, whereas those of United States and Sweden show a more static trend for women with a gradual decline in the Kenyan and Japanese populations. The overall lower FFMI and more rapid decline with age observed in the Kenyan cohort for both men and women compared to other studies may be due in part to poorer nutrition, particularly protein intake; between 2005 and 2007, dietary protein consumption for Kenya was $58 \mathrm{~g} /$ person/day and for United Kingdom, Sweden, United States and Japan was 104, 107, 114 and $92 \mathrm{~g} /$ person/day respectively [36]. Other potential explanations may include higher incidence of disease both infectious and non-communicable, and lower physical activity levels which may be related to comorbidity restriction. However, the differences in the trends observed highlights the need for ethnic-specific reference data on body composition.
The Swedish data show the population FMI to increase between 50 and 61 years and over 75 years [14]. In a slightly older Japanese population of women there was little change in FMI from 65 years to $85+$ years, and this is in contrast to our Kenyan women aged over 55 years in whom FMI progressively declines. Among Swedish men, the FMI increases by $1 \mathrm{~kg} / \mathrm{m}^{2}$ between the two age groups, whereas the Kenyan men exhibited a marginal decline in FMI with age and are more similar to the Japanese older male population who demonstrated a marginal decrease by $85+$ years following a small increase at 75 years [11]. However, the sample size is small, limiting a more detailed interpretation.

Our second objective was to explore the relationship between FFMI and FMI with BP. Our models suggest both FFMI and FMI are positively associated with diastolic and systolic BP. However, there was no evidence to suggest that FMI and FFMI were superior to measurement of BMI alone. These findings are consistent with others studies that show that simple anthropometric measures such as BMI or waist circumference are strongly associated with obesityrelated health risk factors such as high BP [37, 38]. BMI 
Table 3 Estimated marginal mean $(\mathrm{SE})^{\mathrm{a}}$ from descriptive models of participant characteristics in association with body composition status

\begin{tabular}{|c|c|c|c|c|c|c|c|c|c|c|c|c|c|c|c|c|}
\hline & \multicolumn{4}{|l|}{ FFMI } & \multicolumn{4}{|l|}{ FMI } & \multicolumn{4}{|c|}{ FFM to FM } & \multicolumn{4}{|l|}{ BMI } \\
\hline & \multicolumn{2}{|l|}{ Men } & \multicolumn{2}{|c|}{ Women } & \multicolumn{2}{|l|}{ Men } & \multicolumn{2}{|c|}{ Women } & \multicolumn{2}{|l|}{ Men } & \multicolumn{2}{|c|}{ Women } & \multicolumn{2}{|l|}{ Men } & \multicolumn{2}{|c|}{ Women } \\
\hline & Mean & SE & Mean & SE & Mean & SE & Mean & SE & Mean & SE & Mean & SE & Mean & SE & Mean & SE \\
\hline \multicolumn{17}{|l|}{ Age group } \\
\hline $60(n=1314$ from $55-69$ years $)$ & 17.3 & 0.1 & 16.3 & 0.1 & 6.3 & 0.1 & 10.3 & 0.2 & 3.4 & 0.1 & 1.9 & 0.0 & 23.5 & 0.2 & 26.7 & 0.2 \\
\hline $70(n=466$ from $70-79$ years $)$ & 16.8 & $0.1 *$ & 15.9 & $0.1 *$ & 6.2 & 0.1 & 9.9 & $0.1 *$ & 3.4 & 0.1 & 1.9 & 0.0 & 23.0 & $0.1 *$ & 25.9 & $0.2^{*}$ \\
\hline $80(n=188$ from $70-79$ years $)$ & 16.4 & $0.1 *$ & 15.5 & $0.1 *$ & 6.1 & 0.2 & 9.5 & $0.2 *$ & 3.3 & 0.1 & 2.0 & 0.1 & 22.5 & $0.3 *$ & 25.1 & $0.3 *$ \\
\hline $90(n=27$ from $70-79$ years $)$ & 16.0 & $0.2 *$ & 15.1 & $0.2 *$ & 6.0 & 0.3 & 9.1 & $0.4^{*}$ & 3.2 & 0.2 & 2.0 & 0.1 & 22.0 & $0.4^{*}$ & 24.3 & $0.5^{*}$ \\
\hline \multicolumn{17}{|l|}{ Tribe } \\
\hline Mixed $(n=247)$ & 17.1 & 0.2 & 16.0 & 0.2 & 5.8 & 0.3 & 9.6 & 0.4 & 3.7 & 0.2 & 2.0 & 0.1 & 22.9 & 0.4 & 25.6 & 0.6 \\
\hline Kikuyu $(n=1261)$ & 17.1 & 0.1 & 16.1 & 0.1 & 6.4 & $0.1 *$ & 10.2 & 0.1 & 3.3 & $0.1 *$ & 1.8 & 0.0 & 23.5 & 0.2 & 26.3 & 0.2 \\
\hline Kalenjin $(n=487)$ & 16.6 & $0.1 *$ & 16.0 & 0.1 & 5.8 & 0.2 & 9.9 & 0.3 & 3.5 & 0.1 & 2.0 & 0.1 & 22.4 & 0.3 & 25.9 & 0.4 \\
\hline \multicolumn{17}{|l|}{ Residence } \\
\hline Rural $(n=1506)$ & 16.7 & 0.1 & 15.9 & 0.1 & 5.8 & 0.1 & 9.7 & 0.1 & 3.5 & 0.1 & 1.9 & 0.0 & 22.5 & 0.2 & 25.6 & 0.2 \\
\hline Urban $(n=489)$ & 17.5 & $0.1 *$ & 16.5 & $0.1 *$ & 7.3 & $0.2 *$ & 11.3 & $0.3^{*}$ & 3.0 & $0.1 *$ & 1.9 & 0.1 & 24.8 & $0.3 *$ & 27.9 & $0.4 *$ \\
\hline \multicolumn{17}{|l|}{ Education } \\
\hline None $(n=644)$ & 16.5 & 0.2 & 15.8 & 0.1 & 6.1 & 0.2 & 9.3 & 0.2 & 3.4 & 0.2 & 2.0 & 0.0 & 22.6 & 0.4 & 25.1 & 0.3 \\
\hline Primary $(n=934)$ & 16.9 & $0.1 *$ & 16.3 & $0.1^{*}$ & 6.0 & 0.1 & 10.5 & $0.2 *$ & 3.5 & 0.1 & 1.8 & $0.1 *$ & 22.9 & 0.2 & 26.8 & $0.3 *$ \\
\hline $\begin{array}{l}\text { Secondary/college/university }(n= \\
382)\end{array}$ & 17.4 & $0.1 *$ & 16.5 & $0.2 *$ & 6.6 & 0.2 & 11.5 & $0.4 *$ & 3.2 & 0.1 & 1.6 & $0.1^{*}$ & 24.0 & $0.3^{*}$ & 28.1 & $0.5^{*}$ \\
\hline \multicolumn{17}{|l|}{ Smoking } \\
\hline Never $(n=1728)$ & 17.1 & 0.1 & 16.1 & 0.1 & 6.4 & 0.1 & 10.1 & 0.1 & 3.3 & 0.1 & 1.9 & 0.0 & 23.5 & 0.2 & 26.2 & 0.2 \\
\hline Former $(n=128)$ & 16.8 & 0.2 & 15.3 & 1.0 & 6.3 & 0.3 & 10.1 & 2.2 & 3.5 & 0.2 & 1.7 & 0.6 & 23.1 & 0.4 & 25.4 & 3.0 \\
\hline Current $(n=102)$ & 15.6 & $0.2 *$ & 15.2 & 0.8 & 4.5 & $0.3 *$ & 8.6 & 1.7 & 4.1 & $0.2 *$ & 2.8 & $0.4 *$ & 20.2 & $0.4^{*}$ & 23.8 & 2.3 \\
\hline \multicolumn{17}{|l|}{ Alcohol intake } \\
\hline Never $(n=795)$ & 17.1 & 0.2 & 16.2 & 0.1 & 6.3 & 0.2 & 10.2 & 0.2 & 3.5 & 0.1 & 1.9 & 0.0 & 23.3 & 0.3 & 26.4 & 0.2 \\
\hline Former $(n=861)$ & 17.0 & 0.1 & 16.0 & 0.1 & 6.2 & 0.1 & 10.1 & 0.2 & 3.3 & 0.1 & 1.9 & 0.1 & 23.2 & 0.2 & 26.0 & 0.3 \\
\hline Current $(n=305)$ & 16.8 & 0.1 & 15.4 & $0.2 *$ & 6.0 & 0.2 & 8.6 & $0.5^{*}$ & 3.5 & 0.1 & 2.3 & $0.1 *$ & 22.7 & 0.3 & 24.0 & $0.7^{*}$ \\
\hline
\end{tabular}

$* P<0.05$

${ }^{a}$ Results are estimated marginal means (SE) from multivariable linear regression models that included each body composition measure or BMI as the outcome and the demographic characteristics as predictors

remains an inexpensive, easy to implement measure that is strongly associated with increased risk of components of the metabolic syndrome [39, 40] and thus an important screening tool.

The main strength of this study is the focus on older people in Kenya, while previous studies including African ethnicities have all included African Americans. We are unable to account for any bias that may have been imposed in using a follow-up subsample of the cohort, and generally those not included were those whom had died, moved away, were not located or were located but did not come to the examination. This may have affected the representativeness of the initial population sample. BIA was used to measure body composition because it is cheaper and easier to use in the field than reference techniques. BIA has been compared against reference methods such as whole-body dual energy X-ray absorptiometry showing high correlations [41-43], but it is less accurate at an individual level, especially at very high BMIs [43]. Moreover, the bioimpedance measures of body composition rely on predictive algorithms developed using data from diverse populations, mostly Caucasians. However, uncertainty remains over whether these estimates are less accurate for this Kenyan population [44]. Also, the reference values presented in this study are specific to the particular scale used.

An additional limitation is that we used measures of FFM rather than SMM. FFM includes SMM but also organ weight and other non-fat components such as bone mass, while SMM specifically is a more important tissue for the maintenance of glucose homeostasis and potentially a stronger biomarker for metabolic health [45]. While FFM and SMM are strongly correlated, we can only infer that the individuals in the lower centiles may have sarcopenia, a known risk factor for disability, independent of morbidity 
Table 4 Standardized beta coefficients and partial correlations ${ }^{\mathrm{a}}$ relating each body mass measure with BP

\begin{tabular}{|c|c|c|c|c|c|c|c|c|c|c|}
\hline & \multicolumn{5}{|c|}{ Systolic BP } & \multicolumn{5}{|c|}{ Diastolic BP } \\
\hline & $r$ & Beta & $95 \% \mathrm{CI}$ & & $P$ & $r$ & Beta & $95 \% \mathrm{CI}$ & & $P$ \\
\hline \multicolumn{11}{|c|}{ Model $1^{\mathrm{b}}$} \\
\hline BMI & 0.15 & 3.98 & 2.81 & 5.16 & 0.000 & 0.22 & 3.23 & 2.59 & 3.87 & 0.000 \\
\hline FFMI & 0.15 & 3.64 & 2.55 & 4.74 & 0.000 & 0.18 & 2.39 & 1.79 & 2.99 & 0.000 \\
\hline FMI & 0.13 & 3.22 & 2.13 & 4.31 & 0.000 & 0.21 & 2.86 & 2.26 & 3.45 & 0.000 \\
\hline \multicolumn{11}{|c|}{ Model $2^{\mathrm{c}}$} \\
\hline FFMI & 0.07 & 2.61 & 1.03 & 4.18 & 0.001 & 0.04 & 0.68 & -0.18 & 1.54 & 0.119 \\
\hline FMI & 0.03 & 1.51 & -0.61 & 3.63 & 0.162 & 0.06 & 1.60 & 0.45 & 2.75 & 0.006 \\
\hline
\end{tabular}

${ }^{a}$ Results are $r$ (partial Pearson's correlation coefficient) and standardized beta coefficients $(95 \% \mathrm{CI}$ )

${ }^{\mathrm{b}}$ Model 1 adjust for age, gender, tribe, urban/rural, education, smoking and alcohol intake

${ }^{\mathrm{c}}$ Model 2 includes body weight $(\mathrm{kg})$ plus all the other covariates included in model 1

[1]. Nonetheless, this type of population-specific reference data for body composition in the elderly could potentially be used in health checks to identify individuals who may be at risk of sarcopenia, or to monitor changes in body composition over time to identify people with disproportionate losses of FFM, which may lead to frailty. Further research is needed into the relationship between FMI or FFMI and clinical outcomes in prospective cohorts, especially among people of non-Caucasian ethnicity given the known discrepancies between BMI and body composition across different ethnic groups [46] in order to identify clinical thresholds for intervention.

\section{Conclusion}

This study presents novel reference data for FM and FFM in an older Kenyan population and confirmed that FFM is lower in both men and women with increasing age. It also shows a significant decline in FM in women with a smaller decline in men. FMI, FFMI and BMI were all positively associated with systolic and diastolic BP. Both FFMI and FMI show similar associations to those observed with BMI. The trends observed in the Kenyan population may be related to ethnic differences in body composition and highlights the need for ethnic-specific reference data on body composition. Further research should also consider the prospective associations with health, including frailtyrelated outcomes.

Funding This study was supported by the Medical Research Council, Fight for Sight, British Council for the Prevention of Blindness and International Glaucoma Association. MJB is supported by the Wellcome Trust (Grant Number 098481/Z/12/Z). SAJ and CP are funded by the National Institute for Health Research (NIHR) Collaboration for Leadership in Applied Health Research and Care Oxford at Oxford Health NHS Foundation Trust. The views expressed are those of the author(s) and not necessarily those of the NHS, the NIHR or the Department of Health.

\section{Compliance with ethical standards}

Conflict of interest The authors declare that they have no conflict of interest.

Open Access This article is licensed under a Creative Commons Attribution 4.0 International License, which permits use, sharing, adaptation, distribution and reproduction in any medium or format, as long as you give appropriate credit to the original author(s) and the source, provide a link to the Creative Commons license, and indicate if changes were made. The images or other third party material in this article are included in the article's Creative Commons license, unless indicated otherwise in a credit line to the material. If material is not included in the article's Creative Commons license and your intended use is not permitted by statutory regulation or exceeds the permitted use, you will need to obtain permission directly from the copyright holder. To view a copy of this license, visit http://creativecommons. org/licenses/by/4.0/.

\section{References}

1. Baumgartner RN, Koehler KM, Gallagher D, Romero L, Heymsfield SB, Ross RR, et al. Epidemiology of sarcopenia among the elderly in New Mexico. Am J Epidemiol. 1998;147:755-63.

2. Kyle UG, Schutz Y, Dupertuis YM, Pichard C. Body composition interpretation. Contributions of the fat-free mass index and the body fat mass index. Nutrition. 2003;19:597-604.

3. Lukaski HC, Johnson PE, Bolonchuk WW, Lykken GI. Assessment of fat-free mass using bioelectrical impedance measurements of the human body. Am J Clin Nutr. 1985;41:810-7.

4. McCarthy HD, Cole TJ, Fry T, Jebb SA, Prentice AM. Body fat reference curves for children. Int $\mathrm{J}$ Obes (Lond). 2006;30:598-602.

5. McCarthy HD, Samani-Radia D, Jebb SA, Prentice AM. Skeletal muscle mass reference curves for children and adolescents. Pediatr Obes. 2014;9:249-59.

6. Dey DK, Bosaeus I, Lissner L, Steen B. Body composition estimated by bioelectrical impedance in the Swedish elderly. Development of population-based prediction equation and reference values of fat-free mass and body fat for 70- and 75-y olds. Eur $\mathbf{J}$ Clin Nutr. 2003;57:909-16.

7. Saragat B, Buffa R, Mereu E, De Rui M, Coin A, Sergi G, et al. Specific bioelectrical impedance vector reference values for assessing body composition in the Italian elderly. Exp Gerontol. 2014;50:52-56. 
8. Zeng P, Wu S, Han Y, Liu J, Zhang Y, Zhang E, et al. Differences in body composition and physical functions associated with sarcopenia in Chinese elderly: reference values and prevalence. Arch Gerontol Geriatr. 2015;60:118-23.

9. Franssen FM, Rutten EP, Groenen MT, Vanfleteren LE, Wouters EF, Spruit MA. New reference values for body composition by bioelectrical impedance analysis in the general population: results from the UK Biobank. J Am Med Dir Assoc. 2014;15:448.e441-448.e446.

10. Deurenberg P, Deurenberg-Yap M, Guricci S. Asians are different from Caucasians and from each other in their body mass index/ body fat per cent relationship. Obes Rev. 2002;3:141-6.

11. Seino S, Shinkai S, Iijima K, Obuchi S, Fujiwara Y, Yoshida H, et al. Reference values and age differences in body composition of community-dwelling older Japanese Men and women: a pooled analysis of four cohort studies. PLoS ONE. 2015;10:e0131975.

12. Obisesan TO, Aliyu MH, Bond V, Adams RG, Akomolafe A, Rotimi CN. Ethnic and age-related fat free mass loss in older Americans: the Third National Health and Nutrition Examination Survey (NHANES III). BMC Public Health. 2005;5:41.

13. Hull HR, Thornton J, Wang J, Pierson RN Jr, Kaleem Z, PiSunyer $X$, et al. Fat-free mass index: changes and race/ethnic differences in adulthood. Int J Obes (Lond). 2011;35:121-7.

14. Larsson I, Lissner L, Samuelson G, Fors H, Lantz H, Naslund I, et al. Body composition through adult life: Swedish reference data on body composition. Eur J Clin Nutr. 2015;69:837-42.

15. Walley J, Lawn JE, Tinker A, de Francisco A, Chopra M, Rudan I, et al. Primary health care: making Alma-Ata a reality. Lancet. 2008;372:1001-7.

16. Nyirenda MJ. Non-communicable diseases in sub-Saharan Africa: understanding the drivers of the epidemic to inform intervention strategies. Int Health. 2016;8:157-8.

17. Thoma ME, Hediger ML, Sundaram R, Stanford JB, Peterson $\mathrm{CM}$, Croughan MS, et al. Comparing apples and pears: women's perceptions of their body size and shape. J Womens Health. 2012;21:1074-81.

18. Amuna P, Zotor FB. Epidemiological and nutrition transition in developing countries: impact on human health and development. Proc Nutr Soc. 2008;67:82-90.

19. Baumgartner RN, Heymsfield SB, Roche AF. Human body composition and the epidemiology of chronic disease. Obes Res. 1995;3:73-95.

20. Roubenoff R. Sarcopenia and its implications for the elderly. Eur J Clin Nutr. 2000;54(Suppl 3):S40-47.

21. Janssen I, Heymsfield SB, Ross R. Low relative skeletal muscle mass (sarcopenia) in older persons is associated with functional impairment and physical disability. J Am Geriatr Soc. 2002;50:889-96.

22. Rizzoli R, Reginster JY, Arnal JF, Bautmans I, Beaudart C, Bischoff-Ferrari $\mathrm{H}$, et al. Quality of life in sarcopenia and frailty. Calcif Tissue Int. 2013;93:101-20.

23. Landi F, Cruz-Jentoft AJ, Liperoti R, Russo A, Giovannini S, Tosato M, et al. Sarcopenia and mortality risk in frail older persons aged 80 years and older: results from ilSIRENTE study. Age Ageing. 2013;42:203-9.

24. Boyd CM, Xue QL, Simpson CF, Guralnik JM, Fried LP. Frailty, hospitalization, and progression of disability in a cohort of disabled older women. Am J Med. 2005;118:1225-31.

25. Kim TN, Choi KM. The implications of sarcopenia and sarcopenic obesity on cardiometabolic disease. J Cell Biochem. 2015;116:1171-8.

26. Park SH, Park JH, Song PS, Kim DK, Kim KH, Seol SH, et al. Sarcopenic obesity as an independent risk factor of hypertension. J Am Soc Hypertens. 2013;7:420-5.

27. Bastawrous A, Mathenge W, Peto T, Weiss HA, Rono H, Foster A, et al. The Nakuru eye disease cohort study: methodology \& rationale. BMC Ophthalmol. 2014;14:60.

28. Kuper H, Polack S, Eusebio C, Mathenge W, Wadud Z, Foster A. A case-control study to assess the relationship between poverty and visual impairment from cataract in Kenya, the Philippines, and Bangladesh. PLoS Med. 2008;5:e244.

29. VanItallie TB, Yang MU, Heymsfield SB, Funk RC, Boileau RA. Height-normalized indices of the body's fat-free mass and fat mass: potentially useful indicators of nutritional status. Am J Clin Nutr. 1990;52:953-9.

30. Bosy-Westphal A, Muller MJ. Identification of skeletal muscle mass depletion across age and BMI groups in health and disease--there is need for a unified definition. Int J Obes (Lond). 2015;39:379-86.

31. Cole TJ, Green PJ. Smoothing reference centile curves: the LMS method and penalized likelihood. Stat Med. 1992;11:1305-19.

32. Rigby RA, Stasinopoulos DM. Generalized additive models for location, scale and shape. J R Stat Soc Ser C (Appl Stat). 2005;54:507-54.

33. Rigby RA, Stasinopoulos DM. Automatic smoothing parameter selection in GAMLSS with an application to centile estimation. Stat Methods Med Res. 2014;23:318-32.

34. Schutz Y, Kyle U, Pichard C. Fat-free mass index and fat mass index percentiles in Caucasians aged 18-98 y. Int $\mathrm{J}$ Obes. 2002;26:953-60.

35. Tengvall M, Ellegard L, Malmros V, Bosaeus N, Lissner L, Bosaeus I. Body composition in the elderly: reference values and bioelectrical impedance spectroscopy to predict total body skeletal muscle mass. Clin Nutr. 2009;28:52-58.

36. Chartsbin Collector Team. Daily protein intake per capita. Chartsbin.com, 2011. Accessed 01 May 2017.

37. Mooney SJ, Baecker A, Rundle AG. Comparison of anthropometric and body composition measures as predictors of components of the metabolic syndrome in a clinical setting. Obes Res Clin Pract. 2013;7:e55-66.

38. Spiegelman D, Israel RG, Bouchard C, Willett WC. Absolute fat mass, percent body fat, and body-fat distribution: which is the real determinant of blood pressure and serum glucose? Am J Clin Nutr. 1992;55:1033-44.

39. Bray M, Pomeroy J, Knowler WC, Bersamin A, Hopkins S, Brage $\mathrm{S}$, et al. Simple anthropometrics are more correlated with health variables than are estimates of body composition in Yup'ik people. Obesity (Silver Spring). 2013;21:E435-438.

40. Sun Z, Zheng L, Detrano R, Zhang X, Xu C, Li J, et al. Incidence and predictors of hypertension among rural Chinese adults: results from Liaoning Province. Ann Fam Med. 2010;8:19-24.

41. Kyle UG, Genton L, Karsegard L, Slosman DO, Pichard C. Single prediction equation for bioelectrical impedance analysis in adults aged 20-94 years. Nutrition. 2001;17:248-53.

42. Smith-Ryan A, Fukuda D, Moon J, Stout J, Cramer J, Kendall K, et al. Tracking fat-free mass changes in elderly men and women using single-frequency bioimpedance and dual-energy X-ray absorptiometry: a four-compartment model comparison. Eur $\mathbf{J}$ Clin Nutr. 2013;67(S1):S40.

43. Roubenoff R, Baumgartner RN, Harris TB, Dallal GE, Hannan MT, Economos CD, et al. Application of bioelectrical impedance analysis to elderly populations. J Gerontol A Biol Sci Med Sci. 1997;52:M129-136.

44. Ward LC, Heitmann BL, Craig P, Stroud D, Azinge EC, Jebb S, et al. Association between ethnicity, body mass index, and bioelectrical impedance. Implications for the population specificity of prediction equations. Ann N Y Acad Sci. 2000;904:199-202.

45. Sayer AA, Syddall H, Martin H, Patel H, Baylis D, Cooper C. The developmental origins of sarcopenia. J Nutr Health Aging. 2008; 12:427-32.

46. Deurenberg-Yap M, Schmidt G, van Staveren WA, Deurenberg P. The paradox of low body mass index and high body fat percentage among Chinese, Malays and Indians in Singapore. Int J Obes Relat Metab Disord. 2000;24:1011-7. 